\title{
artigo
}

Martinho, N.J.M.; Santos, V.H.M.; Costa, C.M.A.; Marta, C.B.; Morae, R.S.V.; Ramos, K.C.A.R.;

Dificuldades enfrentadas no acesso à saúde por usuários LGBT

\section{Dificuldades enfrentadas no acesso à saúde por usuários LGBT}

\author{
Difficulties faced in the access to health by LGBT users \\ Dificultades enfrentadas al acceso a la salud por los usuarios LGBT
}

\begin{abstract}
RESUMO
Os problemas enfrentados quanto ao acesso aos serviços de saúde pelos usuários LGBT ainda são complexos, de modo específico, nos casos das travestis e transexuais. Este é o recorte de um projeto de pesquisa com abordagem qualitativa, o qual objetiva desvelar as percepções dos LGBT quanto aos atendimentos que recebem nos serviços de saúde de Cuiabá - MT. Foi utilizada a metodologia da roda de conversas para coleta de dados. Os sujeitos referiram despreparo dos profissionais da saúde no acolhimento e atendimento às suas demandas, demonstrando que a academia não os prepara para este tipo de atenção específica e nem as políticas de saúde integral à saúde LGBT estão efetivadas na prática. Espaços de fala e escuta possibilitam aos sujeitos expressarem seus sentimentos e vivências, permitindo-os expressar como deveria ser o atendimento à saúde com equidade e qualidade.

DESCRITORES: Minorias Sexuais e de Gênero; Equidade no Acesso aos Serviços de Saúde; Atenção Primária à Saúde.
\end{abstract}

\section{ABSTRACT}

The problems faced in terms of access to health services by LGBT users are still complex, specifically, in the cases of transvestites and transsexuals. This is the outline of a research project with a qualitative approach, which aims to reveal the perceptions of LGBT people regarding the care they receive in the health services of Cuiabá - MT. The conversation wheel methodology was used for data collection. The subjects reported the health professionals' unpreparedness in welcoming and meeting their demands, demonstrating that the academy does not prepare them for this type of specific care, nor that the comprehensive health policies for LGBT health are implemented in practice. Spaces of speech and listening enable subjects to express their feelings and experiences, allowing them to express how health care should be with equity and quality.

DESCRIPTORS: Sexual and Gender Minorities; Equity in Access to Health Services; Primary Health Care.

\section{RESUMEN}

Los problemas que enfrentan los usuarios LGBT en materia de acceso a los servicios de salud son aún complejos, específicamente, en los casos de travestis y transexuales. Este es el esquema de un proyecto de investigación con enfoque cualitativo, que tiene como objetivo revelar las percepciones de las personas LGBT sobre la atención que reciben en los servicios de salud de Cuiabá - MT. Para la recolección de datos se utilizó la metodología de la rueda de conversación. Los sujetos relataron la falta de preparación de los profesionales de la salud para acoger y atender sus demandas, demostrando que la academia no los prepara para este tipo de atención específica, ni que las políticas integrales de salud para la salud LGBT se implementan en la práctica. Los espacios de habla y escucha permiten a los sujetos expresar sus sentimientos y vivencias, permitiéndoles expresar cómo debe ser la atención de la salud con equidad y calidad.

DESCRIPTORES: Minorías Sexuales y de Género; Equidad en el Acceso a los Servicios de Salud; Atención Primaria a la Salud.

RECEBIDO EM: 15/03/2020 APROVADO EM: 15/03/2020

\section{Neudson Johnson Martinho}

Bacharel e Licenciado em Enfermagem e Tecnólogo em Gestão da Educação Superior. Graduado em Enfermagem pela Universidade de Fortaleza - UNIFOR (1997).

ORCID: 0000-0001-9176-2729

\section{Victor Hugo Martins Santos}

Técnico em eventos pelo Instituto Federal de Mato Grosso - Campus Cuiabá-MT. Graduação em andamento no curso de Enfermagem pela Universidade Federal de Mato Grosso - Campus Cuiabá-MT.

ORCID: 0000-0002-8828-2377 


\section{Cristiane Maria Amorim Costa}

Enfermeira. graduação em Enfermagem pela Universidade Federal do Rio de Janeiro (1985).

ORCID: 0000-0003-1089-2092

\section{Cristiano Bertolossi Marta}

Graduação em Enfermagem pela Universidade do Estado do Rio de Janeiro (2002).

ORCID: 0000-0002-0635-7970

\section{Edneiva dos Santos Bacani}

Graduanda do curso superior nutrição pela Universidade Federal de Mato Grosso.

ORCID: 0000-0003-4901-2961

\section{Rosaní Siqueira Viana Morae}

Graduadaem Enfermagem na faculdade Instituto de Ensino Superior de Mato Grosso.

ORCID: 0000-0003-1075-2161

\section{Karoline Cristine Aparecida Ribeiro Ramos}

Graduada do Curso Superior de Enfermagem pela Faculdade Icec. Campus Universitário de Cuiabá-MT. ORCID: 0000-0002-0737-2726

\section{INTRODUÇÃO}

A LGBTfobia, existente em alguns profissionais da saúde, mostra o despreparo destes durante sua formação acadêmica quanto ao atendimento qualificado às necessidades específicas dos usuários LGBT . A maioria dos profissionais, além do pré-conceito que carregam em si, desconhecem como abordar e cuidar das questôes inerentes às alterações corporais causadas pelo uso de hormônios e silicone, assim como, não têm ações específicas e respeitosas frente a este segmento, que garantam a qualidade do cuidar ${ }^{(1)}$.

Nesse sentido, o direito à não discriminação e à dignidade são humanamente fundamentais. Todas as formas de preconceitos e discriminações, como no caso das homofobias, que compreendem: lesbofobia, gayfobia, bifobia, travestifobia e transfobia, devem ser consideradas na determinação social do sofrimento psíquico que se soma ao surgimento de doenças psicossomáticas ${ }^{(2)}$.

Além disso, a Organização Pan-Americana de Saúde - $\mathrm{OPAS}^{(3)}$ afirma que, comparados com pessoas heterossexuais, as pessoas LGBT apresentam piores condições de saúde causadas pelo estresse crônico e isolamento social, assim como elevadas taxas de depressão e ideias suicidas, ansiedade, consumo abusivo de tabaco, álcool e substâncias psicoativas.
Neste sentido, os problemas de saúde da população de lésbicas, gays, bissexuais e travestis e transexuais (LGBT) são muito complexos, devendo o Sistema Único de Saúde (SUS) empenhar esforços e interesses nas prioridades desse grupo, devido à tamanha violação de direitos e à exclusão social a que está exposto, inclusive nos espaços de cuidado, como os serviços de saúde. A homofobia e preconceitos denunciam a desqualificação na atenção dispensada nos serviços de saúde ${ }^{(4-5)}$.

$\mathrm{O}$ fenômeno supracitado quanto ao não acolhimento e atendimento qualificado as pessoas LGBT sugere que as políticas e programas de saúde integral para estes usuários ainda se configuram como bastante tímidos ou apenas teóricos. Há pouca incidência de ações práticas que legitimem a política nacional de saúde integral à esta população, assim como, o desconhecimento por parte de muitos profissionais da saúde ${ }^{(6)}$.

Frente ao quadro identificado, elaboramos este trabalho, o qual é um recorte do projeto de extensão: "Saúde e políticas públicas: Diálogos, processos educativos e ações propositivas com a população LGBT", cadastrado no SIEX sob n. ${ }^{\circ}$ 080320182122211105 e no Comitê de Ética em Pesquisa da UFMT, com parecer de aprovação n. ${ }^{\circ} 2.740 .579 / 2018$.

Objetivamos com este estudo desvelar as percepções das pessoas LGBT quanto aos atendimentos que recebem nos serviços de saúde de Cuiabá - MT, para com base nas falas apreendidas refletirmos sobre estratégias que possam contribuir a médio ou longo prazo para a efetivação de políticas públicas, melhor acesso e qualidade nos serviços de saúde para estes usuários.

\section{METODOLOGIA}

As ações desenvolvidas no projeto em epígrafe são subsidiadas na Pedagogia de Paulo Freire, através da utilização da metodologia da roda de conversa. Como complemento, a dinâmica da roda de conversa ocorre a partir de um tema gerador do diálogo e com uma dinâmica estimuladora para a participação dos sujeitos. $\mathrm{O}$ método da roda de conversa foi escolhido por possibilitar um espaço de fala e escuta, facilitando a troca de vivências e interação entre os participantes.

O projeto é desenvolvido na Faculdade de Medicina da Universidade Federal de Mato Grosso (UFMT), uma vez por mês, aos sábados no período da manhã. Os participantes são convidados pelas bolsistas de extensão através de redes sociais e contatos diretos. Durante as rodas já realizadas, desde que iniciamos o projeto, tivemos a participação de estudantes de graduação, uma de mestrado, uma professora universitária, psicóloga e uma médi- 
ca, todos pertencentes a sigla LGBT, além de alguns participantes héteros.

Na primeira roda de conversa, trabalhamos o tema gerador "Autoconhecimento e aceitação de si”, utilizamos uma dinâmica que trabalhava a qualidade que cada uma considerava ter a partir do seu nome, seguida de uma reflexão a partir da música "True Colors" interpretada por Cyndi Lauper, a qual aborda a questão de a pessoa ser ela mesma, deixar suas verdadeiras cores aparecerem.

No processo de diálogo e reflexão na roda, surgiram depoimentos de alguns membros sobre como foi enfrentar o preconceito, de modo específico, oriundo da própria família. Outros fizeram observações quanto ao despreparo dos profissionais da saúde para atender os LGBT e a importância desse projeto como espaço para discussões a respeito desta problemática.

Já na segunda roda, o tema gerador foi "A representatividade da sigla LGBT com o enfoque em educação e saúde". Iniciamos com uma dinâmica, a qual consistia em passar uma caixa com palavras-chaves relacionadas ao tema abordado. As palavras selecionadas foram: suporte social, dignidade, apoio, saúde, nome social, inclusão, enfrentamento de preconceitos, qualidade de vida e saúde.

Nessa roda de conversas, trouxemos pessoas que militam pela causa, cada um com sua demanda e particularidades, para estimular o diálogo a partir das vivências de cada um, especialmente em relação à saúde. Entre os convidados que compartilharam suas vivências, estavam um homem gay, uma mulher bissexual, um homem transexual e uma mulher trans. Cada convidado explanou sobre sua experiência em relação à educação em saúde, pois as realidades e dificuldades encontradas podem se diferenciar entre lésbicas, gays, bissexuais, transexuais e Intersexuais.

A troca de experiências, a reflexão e a discussão sobre problemas vivenciados no cotidiano da vida trazem relevantes influências na percepção e ação sobre a vida nas dimensões individual e coletiva, podendo emergir destes espaços de fala e escuta novas atitudes e estratégias de resiliência por
A troca de experiências, a

reflexão e a discussão

sobre problemas

vivenciados no

cotidiano da vida

trazem relevantes

influências na

percepção e ação

sobre a vida nas

dimensões individual

e coletiva, podendo

emergir destes

espaços de fala $e$

escuta novas atitudes

e estratégias de

resiliência por parte

do indivíduo perante

seus enfrentamentos

societais. parte do indivíduo perante seus enfrentamentos societais.

Durante as rodas de conversa, as falas foram sendo anotadas pela observadora e sistematizadas e gravadas pela equipe de dois pesquisadores externos à roda.

Os sujeitos participantes foram representados pela letra correspondente ao tipo de população que estava representando, sendo L para Lésbica, G para Gays, B para Bissexuais, $T$ para Travestis, Transexuais e Transgêneros.

Os números arábicos correspondem ao quantitativo de sujeitos de cada população que participou da pesquisa.

\section{RESULTADOS E DISCUSSÃO}

Após análise dos dados, estabeleceu-se três categorias temáticas, a saber: Desrespeito a identidade de gênero e orientação sexual, Sofrimento psíquico da população LGBT e Ausência de apoio e estrutura nos serviços de saúde.

Desrespeito a identidade de gênero e orientação sexual

"Ocorre desconsideração ao decreto 8.727,28.04.2016 que dispóe sobre o uso do nome social e reconhecimento da identidade de gênero. Falta de políticas progressistas nas escolas" (L1).

"Só se tem um tratamento minimamente digno no sistema único de saúde após ter a sua saúde já comprometida, não se tem essa dignidade garantida antes" (G1).

"Sempre que busco os serviços de saúde, me deparo com profissionais despreparados e falta de sensibilização" (L1).

Sofrimento psíquico da população LGBT

"Tive o psicológico extremamente afetado por ter se assumido muito nova não tinha uma boa relação com a família e não teve um apoio e um tratamento da forma correta na época" (L2). 
"[...] saúde mental muito abalada pela não compreensão e preconceitos na sociedade. Isso desenvolve ansiedade, depressão distúrbios alimentares. E tem levados a muitos tentarem o suicídio" (G2).

\section{Ausência de apoio e estrutura nos serviços de saúde}

"[...] os debates em Cuiabá estão bem fracos este [...] existe um pedido para o hospital universitário Júlio Muller de um ambulatório para atender essa população, porém, esse tramite é muito burocrático" (L2).

"Se faz necessário a existência de uma equipe multidisciplinar especializada, como psicólogo, psiquiatra, endócrino, cirurgião plástico, sexólogo, entre outros" (G1).

"Até hoje os cursos da área da saúde (medicina, enfermagem $e$ outros), ainda não preparam os profissionais para atenderem essa população especifica" (L2).

Todos estas questões apontadas nas categorias evidenciam que os objetivos da política pública para este segmento é uma quimera, como os objetivos II e III, especificamente que vão na contramão da realidade apontada nas falas dos participantes do estudo: "II - ampliar o acesso da população LGBT aos serviços de saúde do SUS, garantindo às pessoas o respeito e a pres- tação de serviços de saúde com qualidade e resolução de suas demandas e necessidades; III - qualificar a rede de serviços do SUS para a atenção e o cuidado integral à saúde da população LGBT"(4).

Assim como o quadro de despreparo da
Consideramos que projetos de extensão que abordem esta

temática estimulam reflexóes propositivas

e movimentos que se concretizem em açốes que a médio e/ou a longo prazo podem contribuir para mudanças necessárias no cenário da saúde LGBT. maioria dos profissionais da saúde no acolhimento e atendimentos a esta população demonstra que as políticas e programas de saúde integral específica para estes usuários ainda se configuram como bastante tímidos e apenas no campo teórico ${ }^{(6)}$.

\section{CONSIDERAÇOES FINAIS}

A problemática em relação ao atendimento nos serviços de saúde nas percepções dos sujeitos LGBT no município de Cuiabá - MT pode assemelhar-se à de outros locais do Brasil, fenômeno que nos leva a inferir que as políticas públicas voltadas para estes usuários no Brasil não se efetivaram de fato, ainda estando muito no campo da teoria e das boas intenções.

Consideramos que projetos de extensão que abordem esta temática estimulam reflexões propositivas e movimentos que se concretizem em ações que a médio e/ou a longo prazo podem contribuir para mudanças necessárias no cenário da saúde LGBT.

Possibilitar espaços de fala e escuta através de rodas de conversa traz em si aspectos terapêuticos no sentido de trabalhar a saúde mental dos sujeitos ao permitir que expressem seus sentimentos e vivências, permitindo-os sair das amarras da repressão que os impossibilita, muitas vezes, de falar, ouvir e serem ouvidos.

\section{REFERÊNCIAS}

1. Mello L, Brito W, Marola D. Políticas Públicas para a população LGBT no Brasil: notas sobre alcances e possibilidades. Cadernos Pagu. 2012 dez; 29: 403-439.

2. Borges GL. Dinâmicas de grupo - redescobrindo valores. 10 ed. Petrópolis: Ed. Vozes; 2008.

3. Organização Pan-Americana de Saúde, Organização Mundial da Saúde. Consejo Directivo 2013. Addressing the causes of disparities in health service acess and utilization for lesbian, gay, bisexual e trans (LGBT) persons. Washington: OPAS/OMS, 2013
4. Ministério da Saúde (BR). Política Nacional de Saúde Integral de Lésbicas, Gays, Bissexuais, Travestis e Transexuais. Brasília (DF): MS, 2010.

5. Brasil. Secretaria de Direitos Humanos. Presidência da República. Relatório sobre violência homofóbica no Brasil. Brasília (DF): Brasil, 2011.

6. Souza MBCA, Helal DH. Política nacional de saúde integral de lésbicas, gays, bissexuais, travestis e transexuais: análise descritiva e utilização de dados secundários para pesquisa e prática. Periódicos UFRN. 2015;1(13):221-251. 